\title{
Superficial Spreading Melanoma
}

National Cancer Institute

\section{Source}

National Cancer Institute. Superficial Spreading Melanoma. NCI Thesaurus. Code C9152.

A type of melanoma that typically occurs in light-skinned individuals ranging in age from young adults to the elderly. Risk factors include extensive sun exposure during childhood, a family history of melanoma, and the presence of dysplastic nevi. 